Pobreza, Exclusión y politización: Trayectoria económica y política de los mapuche durante el siglo XX

Eduardo López Bravo - Fernando Pairican Padilla

Anuario No 32 / ISSN 1853-8835 / 2020

http://anuariodehistoria.unr.edu.ar/ojs/index.php/Anuario/index

\title{
Pobreza, Exclusión y politización: Trayectoria económica y politica de los mapuche durante el siglo XX
}

\section{Poverty, Exclusion and politicization: Economic and political path of the mapuche during the 20th century}

\author{
EDUARDO LÓPEZ BRAVO ${ }^{1}$ \\ Universidad de Santiago de Chile; \\ Universidad Alberto Hurtado (Chile) \\ eduardo.lopezbr@usach.cl
}

FERNANDO PAIRICAN PADILLA ${ }^{2}$

Centro de Estudios Interculturales Indígenas;

Universidad de Santiago de Chile; Universidad Alberto Hurtado (Chile) fernandopairican@gmail.com

RESUMEN

El presente trabajo se propone adoptar la modalidad de ensayo histórico a partir del debate instalado en sectores del mundo académico y el mundo intelectual mapuche emergido en los últimos años sobre los resultados de modernización capitalista en La Araucanía. Constituye una mirada de los autores a la historia de la Araucanía durante el siglo XX, situados desde una perspectiva de mediana y larga duración con el objetivo de una comprensión no solo del pasado, sino que de los desafios pendientes.

1 Doctor en Estudios Americanos, mención Historia, Instituto de Estudios Avanzados Universidad de Santiago de Chile. Magister en Historia de América en la misma casa de estudios. Investigador Asociado del Núcleo de Estudios Asiáticos del Instituto de Estudios Avanzados (IDEA), Universidad de Santiago de Chile.

2 Doctor en Historia - Universidad de Santiago de Chile. Magister en Historia de América en la misma casa de estudios. Investigador Asociado del Centro de Estudios Culturales e Indigenas (CIIR).

Esta obra está sujeta a la Licencia Reconocimiento-NoComercial-Compartirlgual 4.0 Internacional de Creative Commons. http://creativecommons.org/licenses/by-nc-sa/4.0/ 


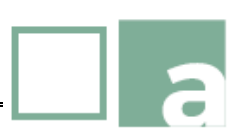

\section{Exclusión y politización: Trayectoria económica y política de los durante el siglo $\mathrm{XX}$}

El análisis se hace a partir de eventos específicos y de los temas que marcaron el debate entre actores políticos, mapuche y empresariales desde la década de los años 30'. De allí que presentemos algunas libertades analíticas tanto en la periodización como en los hitos o coyunturas más relevantes.

Palabras clave: Conflicto Mapuche; Autodeterminación; Plurinacionalidad; Gremios Empresariales.

ABSTRACT

The present work proposes to adopt the historical essay modality starting from the debate installed in sectors of the academic world and the mapuche intellectual world that emerged in recent years on the results of capitalist modernization in La Araucania. It constitutes a look by the authors at the history of Araucania during the 20th century, situated from a medium and long-term perspective with the aim of understanding not only the past, but also the pending challenges. The analysis is based on specific events and the issues that marked the debate between political, mapuche and business actors since the 1930s. In accordance with this is that we present some analytical freedoms both in periodization and in the most relevant milestones or junctures.

Keywords: Mapuche Conflict; Self-determination; Plurinationality; Business Guilds.

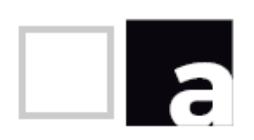

\section{Introducción: E1 problema}

En los últimos 30 años ha pasado a ser un lugar común para un sector de chilenos y, específicamente, para la clase dirigente que los logros económicos nos transformaron en comparación con otros países de la región en "un verdadero oasis en una América Latina convulsionada"3. La respuesta a tan categórica afirmación no tardó en llegar. La tarde noche del 18 de octubre de 2019 el país fue remecido hasta sus cimientos por un estallido social que en lo mediático expresó el descontento ciudadano con el alza de los boletos del

\footnotetext{
3 La frase pertenece a Sebastián Piñera Echeñique. La Tercera 8 de octubre de 2019. Revisar https://www.latercera.com/politica/noticia/pinera-asegura-medio-esta-america-latinaconvulsionada-chile-verdadero-oasis-una-democracia-estable/851913/
}

\section{anuario.}


Metro, pero que en la profundidad del fenómeno fue "la gota que rebalsó el vaso" de la desigualdad económica y social estructural de la sociedad neoliberal chilena. Transcurridos unos meses, existe consenso entre los analistas de la plaza y cientistas sociales que la movilización fue un catalizador de denuncias contra la acumulación de abusos, alzas en los servicios públicos, en los productos de primera necesidad, la precarización de los derechos sociales y el creciente endeudamiento de la población, especialmente, la más pobre con las tarjetas de crédito (Garcés, 2019; Mayol, 2019; Ruíz, 2020; Ponce, 2020).

Los mapuche fueron también actores de este proceso. Expresiones de su movilización las encontramos en masivas marchas en las principales ciudades del sur del país. Novedosas fueron en el repertorio de protesta la destrucción de monumentos contra la historia oficial de la conquista española y la mal llamada "Pacificación de la Araucanía". En Temuco, ciudad a $680 \mathrm{~km}$ al sur de Santiago, se removieron bustos en la Plaza de Temuco y en Concepción la figura de Pedro de Valdivia, fundador de Santiago y principal conquistador español. La cabeza de la escultura fue colgada en la mano del guerrero Kallfülikan, quien representó la resistencia ante el Imperio Español. Adicionalmente, en la ciudad de Collipulli el busto de bronce del general Cornelio Saavedra, se sumaba a la caída de los símbolos del coloniamos. Este militar, empresario del carbón y ganadero, es reconocido por liderar la sangrienta intervención militar en las tierras mapuche en el siglo XIX.

En Santiago, también se sumaron a las movilizaciones "mapuchizando" las manifestaciones. Común fue ver la wenüfoye, bandera que estuvo presente en las principales ciudades del país. También se expresó en el rewe instalado en la principal arteria por los miembros del movimiento mapuche. Todos compartieron el ideal de avanzar en la Autodeterminación y la libertad de los prisioneros políticos (Huenchumil, 2020). Una parte considerable del pueblo mapuche, sobre todo de quienes habitan en las periferias de las principales ciudades, continua sin modificar sustancialmente su realidad socioeconómica, las ideas autodeterminista, en ese escenario continúan siendo una opción y ejercen una hegemonía discursiva en el interior del pueblo mapuche. Esto ha hecho sostener, por lo menos a algunos autores, que nos encontramos en un proceso de multiculturalismo neoliberal (De la Maza, De Cea y Rubilar, 2018).

Una parte significativa de la población mapuche vive en Santiago. Según el Censo del año 2018, el 35\% habita en la capital, mientras que La Araucanía es la segunda región con mayor población situándose con un 18\%. David Aniñir ha escrito que los Mapuche somos hijos de las lavanderas, panaderos, feriantes y ambulantes. "Nacimos en la 'mierdopolis' por culpa del buitre 


\section{Exclusión y politización: Trayectoria económica y política de los durante el siglo $\mathrm{XX}$}

cantor y nacimos en panaderías para que nos coma la maldición". En algún aspecto el movimiento mapuche sintetiza esas dos variables contenidas en la poesía de Mapurbe: ser clase y raza explica en una parte la radicalización del pueblo mapuche (Aniñir, 2000).

La discusión hoy, como antes del 18 de octubre, no son fáciles; sin embargo, el peso de la noche en las carencias del pueblo Mapuche, sobre todo de su bienestar y oportunidades socioeconómicas hacen dificil aceptar que su protesta y la demanda por la autodeterminación sean un tema reciente. Es preciso recurrir a una perspectiva de larga duración para precisar antecedentes y mirar ¿Qué mecanismos de exclusión histórica tanto económicas como políticas se encuentran presentes ayer y hoy en la región de la Araucanía? Se hace necesario clarificar los términos de modernización, modernidad y desarrollo 4 , para luego discutir las politicas aplicadas en una región y cuyos resultados están marcados por la desigualdad, la pobreza y la exclusión.

Este ensayo se divide en tres partes. En primer término, se abordará el proceso traumático de anexión del pueblo Mapuche al Estado Nación chileno durante el siglo XIX y la primera mitad del siglo XX. En segundo lugar, se dedicará al estudio de la economía política en la región durante el siglo pasado, con especial énfasis en eventos específicos donde examinaremos el papel de los actores empresariales en la zona en el conflicto. Finalmente, se realizará un examen de las proyecciones históricas del conflicto social y político entre el Estado chileno y el movimiento mapuche. El estudio, de carácter cualitativo, se realizó en base a análisis de documentos y bibliografia pertinente, así como de información de fuentes primarias recabadas por los autores.

Los elementos de discusión políticos constituyentes en el Chile actual y la solidaridad del pueblo chileno con las demandas del conjunto de los pueblos originarios, permiten mirar con mayor optimismo el futuro del movimiento mapuche. Los altísimos costos sociales y humanos pagados por la población mapuche en el transcurso de dos siglos hacen más ineludible que los historiadores puedan arribar a conclusiones y perspectivas sobre el pasado de un pueblo y una región con los ojos del presente.

\footnotetext{
4 Para los efectos de este ensayo asumimos la propuesta de Norbert Lechner (Flacso, 1990), quien distinguía entre modernización y modernidad. En su perspectiva, modernización hace referencia al desarrollo de la racionalidad instrumental, contraponiéndola a la modernidad en tanto racionalidad normativa. Mientras la modernidad apunta a la autodeterminación política y la autonomía moral, la modernización se refiere a al cálculo y control de los procesos sociales y las fuerzas de naturalezas, las cuales están inscritas institucionalmente resolviéndose los problemas en el sistema político. En lo económico, modernización implica relaciones mercantiles y productivas sin trabas que impidan su desenvolvimiento.
} 


\section{La matriz politica: reducción y pobreza}

El historiador Jorge Pinto ha dedicado su obra a comprender la historia de la frontera. Al igual que Arturo Leiva, han decidido situar su origen con la fundación de Angol, en 1862 (Pinto Rodríguez, 2012, 2015 y 2002). Acompañado del Ejército, empresarios y colonos respaldados por el Estado, los sujetos y sujetas fronterizas ingresaron al Fütalmapu para medir y mapear el territorio mapuche. Con una perspectiva en que unió liberalismo político y económico.

Esta nueva ingeniería política concluyo en la reducción. Un porcentaje de tierras en que los mapuche continuaron viviendo aunque delimitado por la institucionalidad no indígena. Previa a ella existió otro modelo que fue usado en la provincia de Arauco, heredera de la forma hispana en base a los Títulos de Merced. Al interior de esta, el Estado esperaba regenerar a los mapuche a partir de la religión Católica -como fue el modelo aplicado a los wayú en Venezuela y Guaraní en Paraguay-. A partir de esa conversión Católica, insertarlos al modo de producción capitalista del país.

Desde mediados de la década de 1850 se comenzaron a materializar los objetivos del proyecto económico liberal chileno del siglo XIX. La nueva política económica que emergió desde 1860, vino a dar coherencia y respaldo jurídico al modelo de economía abierta desde la independencia. Esta década abrió y cerró lo que Timothy R. Scully denominó la coyuntura crítica de los años 1857-1861(Scully, 1992). Se trató de un momento de ajuste nacional que implicó el abandonó paulatino del modelo autoritario conservador del poder teniendo como telón de fondo un escenario de crisis económica. Paradojalmente, esta dinámica terminará empujando al país a adecuarse con más éxito a las demandas del comercio mundial de productos primarios (Marichal, 1988 y Ross, 2003).

El proceso de ajuste que describimos significó para el país dos guerras civiles, en las cuales participaron los mapuches como actores. En el caso de 1851, un sector encabezado por el Toqui Mañilwenü participó de la insurrección con el propósito de que se aceptaran los acuerdos firmados en los parlamentos que señalaron que desde el río Bio Bío al sur el territorio pertenecía a los mapuche. Este lider mapuche en alianzas con Kallfükurra en Argentina, trabajaron por crear lo que Ingrid de Jong denominó una Confederación Mapuche de la cual también hubiese sido parte el líder mapuche en ngulumapu como se le denomina al sector mapuche entre lo que abarca el Océano Pacífico a la cordillera de los Andes (De Jong, 2010). 


\section{Exclusión y politización: Trayectoria económica y política de los durante el siglo $\mathrm{XX}$}

Los mapuche, tomaron partido por los bandos federales, porque estos permitian espacios de autonomía política. Otro sector liderado por el ñidolongko Venancio Coñuepan planteaba un acercamiento al Estado chileno y la creación de una especie de "política indígena" en base a un reconocimiento de sus liderazgos, en específico el suyo, como Cacique Gobernador a partir del cual se podrian canalizar las divergencias politicas mapuche (Ratto, 2010, Foerster, 2008 y Pairican, 2020).

Mientras los gobiernos Conservadores propusieron una politica indígena en base a los Títulos de Merced, las misiones religiosas como tránsito a la "chilenización" y el reconocimiento a algunas autoridades políticas; los gobiernos liberales usaron esa misma arquitectura, pero como método para insertarlos al modelo capitalista. La experiencia de reducción norteamericana y el modelo de colonialismo francés, pareció apropiado de ser adaptada a las tierras mapuche entre el río Malleco y Cautín. Esa construcción de Estado, fue posible luego de una guerra violenta que, como ha dicho Jorge Pinto, "abrieron una herida que aún no cicatriza" (Pavez, 2008; Inostroza, 1998 y Pinto Rodríguez, 2015).

Desde la perspectiva de José Bengoa, se desarrollaron "diversas formas de integración”. En la perspectiva de la resistencia del pueblo mapuche, podría ser considerada como una "desintegración" del viejo espacio fronterizo, con el fin de acoplar la modernización capitalista liberal desarrollado luego de 1860 (Bengoa, 2000, Pairican, 2020). La política de los gobiernos liberales del siglo XIX hacia los mapuches se situó en la regeneración productiva al capitalismo, pero sin intervenir sus tradiciones y costumbres. Primo el pragmatismo. A diferencia del período conservador, los nuevos gobiernos liberales no se interesaron en sí mismo en la regeneración vía misiones religiosas. La conversión de las almas no era su objetivo, sino más bien que fuesen funcionales a las dinámicas productivas capitalistas (Pairican, 2019). Esta perspectiva, permitió a las reducciones, continuar tejiendo sus redes de parentesco de forma autónoma. Las tradiciones y costumbres -en perspectiva thompseana-, también. Entre otras razones, explica la continuidad de su tejido social hasta avanzado el siglo XX e inclusive XXI.

La "chilenización" se dio en los espacios compartidos con el resto de los habitantes de la república: las escuelas públicas y lugares de trabajo. Las primeras terminaron siendo espacios de adoctrinamiento de la chilenidad, lo que afectó en parte a la niñez mapuche, como dan cuenta algunos testimonios orales. También se aplicó un castigo físico -habitual en las escuelas de la época-, pero entorno a las dificultades de comprensión por parte de la niñez mapuche tomaron ribetes de colonialismo y violencia que fueron recordados en las generaciones del siglo XX (Alvarado y Antileo, 2020).

\section{anuario.}


Varios adultos recuerdan las historias de violencias en las escuelas.

Pero otros se acoplaron al nuevo modelo, desarrollándose como docentes y técnicos en distintos oficios (Ancan, 2000 y Hilger, 2001). No obstante, en las primeras décadas del siglo XX, las reducciones mapuches lograron perpetuar las tradiciones y costumbres pre república. Y si bien algunos pudieron acoplarse al modelo de manera "racializada", por lo menos los más cercanos a los principales poblados productivos, otro número de mapuche sobrevivió en la pobreza extrema. Digamos que a lo menos esas fueron las impresiones de Pablo Neruda en sus recuerdos contenidos en Confieso que he vivido y una parte de la poesía de Jorge Teillier. El primero escribe en sus primeras páginas:

\begin{abstract}
Temuco es una ciudad pionera, de esas ciudades sin pasado, pero con ferreterías. Como los indios no saben leer, las ferreterias ostentan sus notables eblemas en las calles: un inmenso serrucho, una olla gigantesca, un candado ciclópeo, una cuchara antártica. Más allá, las zapaterías, una bota colosa. Si temuco era la avanzada de la vida chilena en los territorios del sur de Chile, esto significaba una larga historia de sangre. (Neruda, 1974: 12).
\end{abstract}

Situados bajo esa realidad, los mapuche se acoplaron al modo de producción que los principales centros urbanos de La Araucanía fueron desarrollando. Trabajadores de temporada, obreros industriales, mujeres de servicio doméstico, entre otros lugares de trabajo. También hubo profesionales de la docencia. Hacia mediados del siglo XX, reconvertirse en un enclave de producción triguera parecía ser su futuro, sin embargo, ese mismo proyecto mostró síntomas de agotamiento hacia 1960, coincidiendo con un cambio generacional con nuevas ideas de transformación en las militancias de partidos y una nueva generación de mapuche que vio en la Reforma Agraria, el cooperativismo y la industrialización, una opción para llevar adelante la recuperación de tierras. (Pinto Rodríguez, 2002 y Correa y Mella, 2012)

De esta manera, se fue gestando un primer ciclo del movimiento mapuche que es posible dividirlo en dos momentos, el primero encabezado por el profesor normalista Manuel Manquilef, fundador de la Sociedad Caupolicán Defensora de La Araucanía (SCDA) en 1910. Este movimiento recuperó el legado del mito ercillano para brindar una subjetividad, un "orgullo" mapuche detrás de estos personajes e incorporarlos en un sentido de incipiente nacionalismo mapuche. Así lo plantea Víctor Naguil (Naguil, 2016). Posteriormente de la SCDA se fundaría una nueva organización bajo el nombre de "Federación Araucana" encabezada por Manuel Aburto Panguilef. Esta organización estuvo influida por los discursos de nacionalismo en Europa a partir del concepto de "araucano" y planteaba el imaginario de una construcción de carácter nacional. Este líder mapuche quedó impactado por el proceso de 


\section{Exclusión y politización: Trayectoria económica y política de los}

durante el siglo $\mathrm{XX}$

descolonización en Israel. La construcción nacional en ese país los llevó a dilucidar como factible la construcción de una nación independiente, declarando, a mediados de la década del 40' su aspiración de construir una Republica mapuche o Araucana (Menard, 2013).

Una tercera estrategia se relaciona con el mundo empresarial encabezado por Venancio Coñuepan. El fundador de la "Corporación Araucana" provenía de una familia vinculada a líderes que forjaron alianzas con los republicanos desde sus origenes como Bernardo O’Higgins y luego con los presidentes de la República Conservadora. La familia Coñuepan junto a los Kolüpi fueron engranajes de la creación de una política indígena que concluiria con la negociación de las reducciones de tierras. Coñupean a mediados del siglo XX, tomo partido por el modelo desarrollo en base al emprendimiento empresarial. Apuesta que significó detractores y también apoyo de algunos longko mapuche. (Ancan, 2010). En la arena política, sus alianzas se vincularon al Partido Conservador y luego como ministro del segundo gobierno del General Carlos Ibáñez del Campo.

Coñuepan fue organizador, presidente y gerente de la Caja Central de Indigenas. Una instancia con la que se esperaba que los mapuche optaran a créditos para emprendimientos económicos y se organizaran en cooperativas para su desarrollo económico. Coñuepan llegó en algún momento a presidir la Sociedad de Fomento Agricola de Temuco (Cayuqueo: 2020).

La historia post Ocupación de La Araucanía se situó en una dicotomía. Sobrevivieron los mapuche bajo un modelo de reducción estilo norteamericano, y a su vez, la apuesta a una industrialización permitió un crecimiento de algunos líderes mapuche que se complementaron a ese modelo industrial que, pese a todo, como ha dicho Jorge Pinto, no logro consolidarse quedando en un caso frustrado de desarrollo (Pinto Rodríguez, 2020). Entre otras variables explicaría las razones de un deseo de sumarse a la reforma de la tierra a mediados de la década de los 60'. Pero ello respondió a las variables que se relacionan con las matrices económicas, las ideas políticas mapuche y el contexto internacional entorno a la reforma de la tierra. El "desarrollo frustrado" de la provincia de Cautín terminó por generar una suma de variables que en la década de los cincuenta radicalizó la cuestión étnica.

\section{La matriz económica: modernización capitalista subordina, pobreza y exclusión}

Del estudio de la economía política en la Araucanía durante el siglo XX se puede concluir que la región contó con una estrategia de desarrollo económico 
insuficiente o, podría incluso señalar, ausente. En rigor, la incorporación tardía de la región al Estado Nación chileno - mediante la ocupación militar setenta años después del nacimiento como república independiente - definió en gran medida el devenir económico subordinado de la macrozona a las lógicas de expansión productiva sin transformaciones estructurales del desarrollo capitalista chileno del último cuarto del siglo XIX.

Diez años después de asentada la ocupación militar en la Araucanía, una extensa red ferroviaria insertó a la región en el dominio del Estado chileno bajó prácticas productivas y laborales de "antiguo régimen"; esto quiere decir, en los marcos de la explotación al máximo de sus recursos naturales, el reforzamiento de la estructura de la gran propiedad y la provisión de una mano de obra donde la intermediación del salario era muy limitada (Pinto Rodríguez, 2015) Se trató de una época donde la sabiduría convencional empleo el término del "granero de Chile" para referirse a este espacio fronterizo.

Durante el periodo de post-ocupación comprendido entre 1883 y 1940, la Araucanía desarrolló una economía donde la producción triguera sería el pilar más importante, pero también alcanzan un rol muy significativo la ganadería y la actividad forestal, las que se hicieron cada vez más trascendentales en la medida que avanzó el siglo XX. Los grandes productores se vincularon a la economía nacional e internacional, y con el tiempo fueron desarrollando una mayor especialización productiva (Flores, 2006; Henríquez, 2013).

Las historias locales que se han escrito en la frontera han destacado, en un lenguaje elocuente y casi barroco, el desarrollo extraordinario de la producción triguera, ayudando a alimentar el mito de la abundancia cerealera en la zona:

En segundo lugar citaremos la producción de trigo, factor principal que marca la riqueza de un Departamento: pues durante la última cosecha se han remitido a diversos puntos de la costa más de doscientos mil hectolitros de dicho cereal, que dieron quehacer al ferrocarril hasta entradas de invierno, a pesar de que, a más de los trenes ordinarios de carga uno especial para llevar trigo venía semanalmente de Talcahuano a solicitud de muchos agricultores $i$ comerciantes del ramo, que desesperaban al ver que no disminuian, a pesar del acarreo diario, los cerros permitasenos la expresión, de trigo que casi llenan la extensa estación del ferrocarril (Gallegos y Padilla, 1978, p. 103)

La fase de "crecimiento hacia afuera" en la Araucanía se extendió con éxito relativo hasta inicio de la década de 1940, a contrapunto de la estrategia de "crecimiento hacia adentro" que se implementaba desde fines de los años 1930 en el país. El modelo productivo regional descansó bajo cuatro supuestos 


\section{Exclusión y politización: Trayectoria económica y política de los durante el siglo $\mathrm{XX}$}

básicos: a) la presencia de grandes y medianos productores que aprovecharon abundantes territorios obtenidos a costa de sus antiguos dueños; b) una amplia disponibilidad de recursos naturales; c) alta demanda en el mercado nacional de la producción triguera y ganadera y, finalmente, d) una abundante mano de obra de peones y colonos de Chillán, Cañete y Lebu que se concentraron en la producción agrícola. En esta matriz la población mapuche no fue absorbida laboralmente, quedando excluida y confinada a las reducciones o como destacaremos en la modalidad de trabajo estacional, obreros industriales y el servicio doméstico femenino.

La alteración de cualquiera de estos supuestos tendría efectos negativos sobre la actividad exportadora. En este sentido, el origen de la crisis y la contracción económica en la región desde la década de 1940 fue el resultado del agotamiento de una construcción histórica, provocada por la sobreexplotación de los recursos naturales y los rendimientos decrecientes en la agricultura. La ausencia de emprendimientos productivos articulados y de políticas de fomento estatales para el incipiente sector industrial contribuyeron al débil o limitado desarrollo de mercados de factores regionales para enfrentar la crisis de la matriz exportadora regional (Flores, 2011).

La región entró en su propia crisis de matriz exportadora cuando a nivel nacional se observaron claros signos de agotamiento de la fase clásica de industrialización por sustitución de importaciones (ISI). En efecto, la segunda mitad de 1950 estuvo marcada por el deterioro de la economía, el aumento del proceso inflacionario, la desaceleración de las tasas de crecimiento, el incremento de la conflictividad social y una aguda crisis política que puso en jaque la vigencia del sistema democrático. Son los años en que dos influyentes intelectuales e inspiradores de los proyectos económicos de la década de 1960 señalaron que el país vivía una "crisis integral", como sostuvo Jorge Ahumada, o que nos encontrábamos frente a "un caso de desarrollo frustrado", en palabras de Aníbal Pinto. (Ahumada, 1958; Pinto, A., 1959).

Tan importante como el desempeño de los sectores económicos y sus indicadores, fueron los procesos sociales que se verificaron a nivel regional. Entre 1931 y 1965 emergieron múltiples conflictos territoriales, marcados por la usurpación de tierras y procesos divisorios al interior de los Títulos de Merced, lo cual se tradujo en la reducción de cerca de 100 mil hectáreas la propiedad mapuche, aumentando las demandas por la restitución territorial con nulos resultados para sus originales dueños (Correa y Mella, 2012). Las demandas por la restitución de las tierras a nivel regional se instalaron en el marco del radicalismo programático a nivel nacional para la solución de los problemas sociales y económicos que se configuró en los años sesenta. En rigor, todos los sectores políticos del país compartieron como criterio generalmente aceptado el desfase de los diseños políticos, sociales y 
económicos gestados con la restauración de la década de 1930

(López, 2020). Aun cuando presentaron matices y diferencias ideológicas importantes, todos terminaron asumiendo el cambio de las estructuras económicas vigentes como alternativa de solución. Desde el centro, el antiguo pragmatismo radical fue desplazado por una nueva fuerza politica de características programáticas e ideológicas: la Democracia Cristiana. Por lado de la izquierda, los dos principales partidos del sector - el comunista y socialista - lograron (con dificultades) forjar una alianza que perduró prácticamente por dos décadas. En la derecha se vivió el comienzo de una etapa decisiva y que implicó al finalizar la agonía de la derecha oligárquica y la emergencia de una fuerza política renovadora: el gremialismo universitario de la Universidad Católica de Chile (Valdivia, 2008).

¿Qué ocurrió en la Araucanía con el triunfo de la Unidad Popular (UP)? La política económica del gobierno de Salvador Allende se propuso transformar radicalmente la propiedad de los medios de producción y aumentar la participación popular en la distribución del poder político y económico, todo lo cual implicaba una redefinición del derecho de propiedad (Salazar y Pinto, 2002). El combate contra la gran propiedad, por tanto, generó las condiciones para que la demanda mapuche se insertase en el proyecto político nacional de la UP, al punto que las organizaciones mapuches se transformaron en una realidad permanente durante esta breve experiencia. En efecto, el proyecto revolucionario estuvo básicamente orientados a la redistribución de tierras a los campesinos no mapuche y la restitución de ellas a la población mapuche. La pregunta que puede formularse es ¿cuál fue la masividad de este proceso? La respuesta puede encontrarse en las palabras de un hombre clave en la conducción del proceso económico en los últimos meses del gobierno, José Cademartori, último Ministro de Economía del gobierno de Salvador Allende, para quien el proceso de transferencia de tierras a las comunidades indígenas fue de 70 mil hectáreas. Otros autores calcularon cerca de 200.000 hectáreas (Samaniego y Ruiz, 2007).

Inicialmente, la Unidad Popular no logró comprender en toda su dimensión la situación específica de despojo y exclusión del pueblo mapuche. En su viaje a Cautín el ministro de Agricultura Jacques Chonchol sostuvo en 1971:

Nosotros no creemos que en el fondo haya aqui un problema de indigenas o de no indigenas [...] No es un problema racial sino un problema de campesino pobre, explotado y oprimido a muchos de los cuales les han robado las tierras por generaciones con métodos legales o no legales [...] No es un problema fácil de resolver, la población mapuche de Cautín es del orden de las 200 mil personas: es un problema que se ha venido postergando indefinidamente y que esperamos no resolverlo, pero en fin, tratar de comenzar a abordarlo (Urrutia, 2019). 


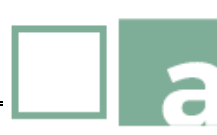

\section{Exclusión y politización: Trayectoria económica y política de los durante el siglo $\mathrm{XX}$}

Como sugiere Daniel Barnaby, los colonos agricultores observaron el giro hacia la izquierda que estaba teniendo lugar por toda la región de la Araucanía como un escenario de amenaza e incertidumbre del viejo orden. En el caso de Cautín, el legado de la 'pacificación' llevó a los colonos agricultores a creer que 'sus propios' campesinos y las comunidades indigenas cercanas podrian mantenerse bajo control a través de una combinación de la sumisión tradicional y la anticuada coerción ejercida en los territorios fronterizos recién conquistados entre los años 1890 y 1920 (Barnaby, 2017). Lo anterior es ilustrativo de uno del déficit del conjunto del proceso de Reforma Agraria en la Araucania: las disputas de tierra entre los agricultores y las comunidades mapuche tenían un origen profundo y que se remontaba a la toma fraudulenta de tierras de las comunidades mapuches por los fundos adyacentes, tierras a menudo vendidas posteriormente, lo que creaba situaciones en las que ambas partes podian reclamar derecho legal sobre el predio en cuestión.

Cabe destacar que la lucha por la tierra se convirtió desde mediados delo siglo $\mathrm{XX}$ en una demanda creciente en países con alta presencia indigena; como el caso Bolivia, Perú, Ecuador, México y Guatemala. La situación mapuche, con sus diferencias, se sumó a ese proceso continental en que los proyectos reformistas intentaron solucionar la concentración de la tierra y que en algunos países adquirieron una dimensión revolucionaria. En Bolivia la revolución de 1952 impulsará una reforma agraria de carácter campesina que será criticada por algunos sectores del movimiento indígena, aunque fue clave para comprender los movimientos posteriores en este país. Aspecto similar sucedió en Perú, donde el presidente Juan Velasco Alvarado recuperará la figura de Túpac Amaru como símbolo de su movimiento que repercutirá en las organizaciones políticas. En ese escenario las escrituras del pensador José Carlos Mariátegui volvieron a ser reinterpretadas y editadas para comprender la situación indígena en el Perú (Mariátegui, 2007).

Bajo este escenario el proceso de reforma agraria en Chile de la década de 1960 no incursionó - y no era su propósito - en el significado social y simbólico de la tierra para las comunidades mapuches y latinoamericanas. En efecto, la demanda mapuche por la tierra fue leída y asimilada en muchas ocasiones por los tecnócratas estatales como un problema no muy diferente a los campesinos pobres del valle central. Con todo, los mapuche se sumaron a los gobiernos que promovieron la reforma agraria. En específico bajo la Unidad Popular desplegaron sus fuerzas para recuperar las tierras históricas; es decir, las que se encuentran presentes en los Títulos de Merced que fueron apropiados por los colonos luego de la Ocupación de La Araucanía. De esta manera, los mapuche en la provincia de Cautín desplegaron como repertorio de acción colectiva la "corrida de cercos", lo cual generó la respuesta por parte

\section{anuario.}


de los agricultores a través de la organización de Comités de Recuperación de Tierras de manera violenta.

En opinión de Martín Correa, desde la perspectiva mapuche durante la aplicación de la reforma agraria en la región se articularon tres memorias colectivas de la tierra. La primera la memoria histórica, esas que recuerdan los más antiguos de las comunidades como los límites originales. La segunda, asociadas a los Títulos de Mereced y Reducción. Finalmente, la tercera corresponde a las tierras recuperadas durante la Reforma Agraria que luego serian vueltas a perder por la contra reforma implementadas por el gobierno cívico militar de Pinochet 5 . Estas tierras puestas al mercado fueron luego compradas por los empresarios asociados a la industria forestal, comenzando una nueva etapa histórica en relación con la propiedad, empresarios y el surgimiento de un segundo ciclo del movimiento mapuche (Pairican, 2013). A esa chilanizacióna neoliberal se respondió con el derecho a la Auodeterminación, que derivó en el transcurso de mediados de la década de los 90' en un proceso de Liberación Nacinal Mapuche.

\section{Las politicas neoliberales: rearticulación empresarial y el impulso forestal}

El golpe militar de 1973 marcó la entrada de las políticas neoliberales a la región y el proceso de contra reforma agraria cuyos costos sociales se expresaron en la intervención de las organizaciones campesinas para erradicar definitivamente el marxismo y controlar la población indígena mediante la creación de fuentes de trabajo que asegurasen su integración a la comunidad nacional. (Pinto, J., 2015). Tomando como insumo los últimos trabajos que han examinado este periodo, la llegada de los Chicago Boys al control del aparato estatal implicó la aplicación de un tratamiento de shock que condujo a la destrucción de una parte no menor de empresas, enormes rebajas de aranceles a las importaciones, la radical liberalización del mercado de capitales, el ajuste del presupuesto fiscal, cambios tributarios y la completa liberalización de precios tuvieron un profundo efecto en la agricultura y la industria (Gárate, 2012; Ffrench-Davis y Stallings, 2001). A nivel regional, las medidas neoliberales implicaron la reducción del apoyo estatal y la internacionalización forzosa obligó a los empresarios agrícolas, lecheros y ganaderos a competir a nivel nacional. Hacia 1980 las áreas rurales

\footnotetext{
5 Adoptamos el concepto Cívico - Militar de Carlos Huneeus (2016) quien constata la decisiva participación de civiles durante los 17 años de la Dictadura de Pinochet. Desde esta perspectiva interpretativa fueron los civiles quienes diseñaron e implementaron las principales reformas económicas e institucionales del régimen militar.
} 


\section{Exclusión y politización: Trayectoria económica y política de los durante el siglo $\mathrm{XX}$}

mostraban un comportamiento profundamente deficiente, con un campesinado socialmente debilitado y con escasas posibilidades de acceder al crédito. En este escenario, las transferencias tecnológicas desaparecen y los magros rendimientos alcanzados por la agricultura no campesina se expresó en un cuadro de recesión con indicadores de desempeño muy pobres. Al finalizar la dictadura de Pinochet, la región mostraba los más altos índices de pobreza e indigencia del país, indicadores que no mostraron sintomas de mejora hasta el año 2003. De acuerdo con el ranking de competitividad del Programada de las Naciones Unidas para el Desarrollo (PNUD) de 1992, en las 13 regiones del país, la Araucanía alcanzaba el lugar número 11 en el rubro desarrollo económico, el 13 en personas, el 11 en infraestructura y el 6 en recursos naturales (PNUD, 1996).

Para una zona socialmente resentida, los efectos de la estagnación económica se hicieron particularmente extremos en las comunidades mapuches, quienes vivieron bajo el "peso de la noche social y económica neoliberal". De acuerdo con el informe elaborado por el Ministerio de Desarrollo y Planificación (MIDEPLAN) y el Instituto Nacional de Estadística (INE) el año 2002, la región no sólo perdió representatividad en términos poblacionales en el país con un $5,76 \%$, sino que el Producto Interno Bruto creció durante toda la década de 1990 a un ritmo menor que el resto del país (MIDEPLAN-INE, 2001; Pinto, J. 2015). Con todo, la agricultura continuó siendo el motor económico de la región hasta entrada la década del 2000.

La acumulación de problemas sociales y económicos producto de la aplicación ortodoxa de las políticas neoliberales también fueron una fuente de conflicto para el mundo empresarial agrícola en la región de la Araucanía. Los sacrificios que imponían las medidas económicas de los Chicago Boys fueron tolerados por las grandes asociaciones empresariales más representativos de los grandes empresarios, quienes privilegiaron el apoyo político al régimen militar por sobre sus intereses frente al temor de una vuelta al radicalismo político de los sesenta. Sin embargo, la exclusión de la participación de los gremios representativos de la pequeña y mediana agricultura, de igual modo que de la industria lechera, tuvieron como resultado la emergencia del desencanto y la crítica al esquema neoliberal en su versión más ortodoxa entre 1975 y 1982 (Arriagada, 2004). Como han destacado Guillermo Campero y Fabián Almonacid, si bien los pequeños y medianos empresarios respaldaron las definiciones generales de las políticas neoliberales (especialmente en lo concerniente a la devolución de tierras expropiadas), se manifestaron abiertamente contrarios cuando fueron afectados por la liberación de precios y la rebaja de aranceles a las importaciones de productos que competían directamente con su producción. La situación los empujó a una espiral de conflicto con el gobierno, demandando y negociando cambios concretos al

\section{anuario.}


ritmo e intensidad que exigian las políticas económicas monetaristas en la región (Campero, 1984; Almonacid, 2016).

Con diferentes intensidades, la creciente oposición gremial al neoliberalismo contó con el protagonismo de la Confederación de Productores Agrícolas (CPA), el Consorcio Agrícola del Sur (CAS), dirigidas por Sergio Durán, y de agrupaciones menos organizadas de trigueros y remolacheros de la Araucanía, Valdivia y Osorno. Expuestos los empresarios agrícolas, especialmente la industria lechera, al vértigo de los precios internacionales y a la competencia de importaciones que generalmente recibían subsidios en sus países de origen, se producirá la primera rebelión gremial de importancia que conoció el período del gobierno cívico militar de Pinochet. El conflicto entre el gobierno y los gremios empresariales de la zona sur del país escaló a niveles inusitados de violencia verbal, cuando un funcionario del Ministerio de Economía recomendó al sector que "se coman las vacas" producto de la imposibilidad de competir con la leche importada (Gómez y Echeñique, 1988). Con todo, y pesar de la oposición de la tecnocracia neoliberal enquistada en el gobierno, en octubre de 1977 se fijó un arancel específico de catorce productos lácteos que favorecía al sector para continuar desarrollándose.

Las tensiones entre los productores tradicionales y las medidas neoliberales se agudizaron entre 1981 y 1982. En efecto, el endeudamiento del sector a causa del creciente debilitamiento del mercado interno, derivando en la cesación de pagos de créditos adquiridos y la quiebra de empresas agroindustriales dedicadas al procesamiento de remolacha y leche. La crisis condujo a la más importante oleada de movilizaciones y protestas de los productores agrícolas de las ciudades de Rancagua, Temuco y Valdivia durante todo el año 1982. El resultado, se resolvió por los mecanismos clásicos de atenuación de la protesta de los empresarios agrícola. En el caso de los productores agrícolas tradicionales, el gobierno fijó bandas de precio cuya finalidad era defender la producción local de trigo, leche, cereales y todos aquellos bienes que se orientaban al mercado interno. Además, se definieron condiciones de repactación de deudas para atenuar los problemas financieros que aquejaban a los productores agrícolas (Montero, 1997; Arriagada, 2004).

Se resolvía transitoriamente un problema fundamental del mundo empresarial tradicional en las regiones centro y sur del país, y, por cierto, clave en la interpretación de su comportamiento sociopolítico: la defensa de sus patrimonios, sean estos territoriales o de unidad productiva. Paradojalmente, si los pequeños y medianos empresarios agrícolas observaron un cuadro de amenaza a sus intereses entre 1967 y 1973 bajo la versión socialista de las expropiaciones y estatizaciones territoriales; entre 1977 y 1983 la 


\section{Exclusión y politización: Trayectoria económica y política de los durante el siglo $\mathrm{XX}$}

incertidumbre provenía de la competencia externa y la caída de la demanda interna; lo cual implicaba perder sus tierras para enfrentar la deuda (Lovera, 2017; Arriagada, 2004).

Respecto al sector forestal, durante la década de los años de 1960 aumentó su participación en la región como resultado de las políticas de incentivos iniciadas por la Corporación de Fomento de la Producción (CORFO). En efecto, desde 1965 la zona entró en un proceso de "pinificación" bajo el impulso de las políticas de planificación central del gobierno de Eduardo Frei. Sin embrago, desde 1978, los grandes empresarios forestales hacen su aparición formal en la Araucanía cuando la Corporación Nacional Forestal (CONAF) procedió al remate de importantes extensiones territoriales a precios irrisorios y generosas bonificaciones en los costos netos de forestación, la cuales alcanzaban hasta el $75 \%$.

Al finalizar la década de 1980, la región experimentó la disolución de la propiedad colectiva de la tierra, y si bien los decretos leyes $\mathrm{N}^{\circ} 2.568$ y $\mathrm{N}^{\circ}$ 2.7750 de 1979 prohibía la enajenación de las hijuelas resultantes del proceso de división, lo concreto fue que muchas de esas tierras mapuches fueron traspasadas a no indígenas mediante transacciones fraudulentas que implicaron en muchas ocasiones arriendos por un periodo de 99 años (Gómez, 1999; Pairican, 2014). Junto con la desintegración de la propiedad comunal de la tierra indigena, la dictadura impulsó un proceso de inversión forestal en territorio mapuche. Entre 1976 y 2010 el Estado invirtió en el sector US\$ 474, 3 millones en la industria forestal, de los cuales solo un 33,7\% favoreció a pequeños empresarios forestales (Pinto, J., 2015). Transcurridos 15 años, tres grandes consorcios forestales lograron monopolizar el $70 \%$ de las ganancias totales del sector forestal chileno. De acuerdo con los datos que aportan Cristián Frene y Mariela Núñez, Celulosa Arauco (del grupo Angelini), la CMPC (del grupo Matte) y MASISA controlaron hacia 1997 el 94,2\% de las plantaciones forestales en la región. Las utilidades acumuladas por estas empresas entre 2000 y el 2005 superaron los 2.268 millones de dólares. En tanto, CMPC obtuvo por si solas ganancias superiores a 230 millones de dólares, acumulando para igual período un total de 1.369 millones de la moneda norteamericana. Las utilidades de Celulosa Arauco alcanzaron el año 2012 los 141 millones de dólares. Por su parte MASISA también reconoció utilidades por 84,2 millones de dólares (Frene y Núñez, 2010).

Desde el punto de vista de la economía política regional, ¿Por qué son importantes estas cifras? La respuesta es compleja dada la gran cantidad de elementos a conjugar en una zona marcada por el signo de la exclusión y la apropiación territorial. En esta nueva fase de la matriz exportadora en la región, ahora en clave neoliberal, el modelo productivo forestal se articuló en función de cuatro supuestos fundamentales: a) abundantes territorios 
obtenidos a costa de los antiguos dueños mapuche; b) una amplia disponibilidad de recursos forestales subvencionado por el Estado; c) alta demanda desde el mercado internacional; y c) una demanda de mano de obra muy acotada. Repitiendo una vez más la trayectoria del despojo territorial en la región, el modelo productivo que instalaron las empresas forestales se edificó sobre la base del control irregular y con escasa transparencia de las tierras que habian sido expropiadas en favor de campesinos y mapuches en el marco de la Reforma Agraria.

Adicionalmente, el proceso de cambio económico o desarrollo capitalista que privilegió la dictadura era parte de un todo mayor: la formación de grupos económicos capaces de crear las condiciones para su diseño e implementación. Por estos motivos, los Chicago Boys estimularon la formación de grupos económicos a partir de las privatizaciones, porque estaban convencidos de que era esencial contar con conglomerados empresariales poderosos que en economías de escala como el sector forestal permitieran modernizar las empresas y llevarlas a competir en los mercados internacionales. Esto tuvo como consecuencia a nivel nacional y, particularmente, en la Araucanía una concentración económica nunca vista. El proceso privatizador de las empresas y de los territorios de CONAF en la región condujo a una recomposición del mapa de los grupos económicos (Nazer, 2013) que introdujo cambios sustanciales en la tenencia de la tierra, del trabajo, del medio ambiente y para el pequeño agricultor mapuche. Paradojalmente, la Araucanía finalmente consolidó una estrategia económica regional que la incorporó dentro de un proyecto de modernización económico nacional de corte neoliberal con costos sociales profundos.

Los mapuche observaron como las forestales se apropiaron de su territorio histórico y luego de los recuperados bajo la Reforma Agraria. Algunas plantaciones pensadas para su proyecto de desarrollo colectivo también terminaron en manos de los empresarios, de ese modo, la crítica a esa nueva “usurpación” explicaría en los 90' una variable de la rebelión del movimiento mapuche. La empresa forestal fue uno de los grandes proyectos de la dictadura militar, Joaquín Lavín lo asociaba a un nuevo cobre para el país (Lavín, 1987). Estas plantaciones fueron posibles bajo el régimen cívicomilitar, pues las tierras recuperadas bajo la Reforma Agraria fueron devueltas al Estado vía CORFO, luego puestas al mercado y vendidas a un bajo costo para ser adquiridas por un nuevo tipo de empresarios: el forestal que se pensaba como un pilar de la revolución neoliberal (Gárate, 2012).

En la provincia de Arauco los mapuche vieron como sus tierras recuperadas bajo la Reforma Agraria terminaron como propiedad de las empresas 


\section{Exclusión y politización: Trayectoria económica y política de los durante el siglo $\mathrm{XX}$}

forestales. Este hecho marcaría a futuro una de las variables de las protestas mapuche al observar como sus tierras terminó en poder de los futuros conglomerados de la década de los 90'. La segunda crítica por parte de los mapuche se relaciona a un aspecto ambiental. Las forestales generaron una sequía en menos de una década y un cambio en la diversidad de la flora y fauna. En una tercera variable por el modo de producción de la empresa no genero trabajos ni una mejoría económica como fueron las promesas iniciales. Hacia 1997 los mapuche continuaban estando en niveles de pobreza no menor en contraste con el rubro forestal que alcanzaba niveles altos de rentas. (Moulian: 1997). ¿Cómo se explica? La respuesta se encuentra en el itinerario que siguió la transición democrática en la década de los años 90' y los actores clave de este proceso: los empresarios, los gobiernos de la concertación y el movimiento mapuche.

\section{Los largos años noventa: Los empresarios frente a la estrategia autonomista del movimiento Mapuche}

¿Qué ocurrió con la llegada de los años 90’? Como lo han resaltado los principales analistas de este período, la decisión económica (y por tanto política) de las fuerzas de centro izquierda agrupadas en la Concertación de Partidos por la Democracia fue mantener lo esencial del modelo neoliberal. Los nuevos gobiernos de la concertación desde una posición pragmática respetaron los fundamentos del llamado "modelo" y ampliaron los beneficios de la inversión extranjera, lo cual redundó en una avalancha de inversión extranjera que entre 1990 hasta el 2010 alcanzó los 72 mil millones de dólares. Ciertamente la decisión de la continuidad de las politicas monetaristas tuvo un efecto tranquilizador en las asociaciones empresariales del gran empresariado nacional, quienes estuvieron alertas a la posibilidad del rebrote populista o estatista, el aumento del gasto público, la discusión de la carga tributaria o la rigidez del mercado laboral vía agenda legislativa. Como sostiene Rolando Álvarez, durante el período 1990 y 2000, el gran empresariado, utilizando su amplio repertorio de acción política defendió el legado económico e institucional del régimen militar (Álvarez, 2015). Correspondió a la Confederación de la Producción y el Comercio (CPC) y la Sociedad de Fomento Fabril (SOFOFA) liderar la voz de los gremios nacionales, asumiendo una opción confrontacional con los gobiernos concertacionistas, comprometiéndose en una acción política más propiamente de partidos.

Desde una perspectiva nacional, los gremios empresariales, a diferencia de cualquier otra etapa histórica del país, se asumieron como un bastión no tan solo de la defensa de la iniciativa privada o de la propiedad de su patrimonio, sino que como parte de una alianza de defensa del modelo y la obra

\section{anuario.}


institucional del régimen de Pinochet. En este sentido, los grandes gremios empresariales formaron parte de los tres dispositivos extrainstitucionales que en opinión de Antonio Cortés Terzi se organizaron para la defensa del legado de la dictadura. La primera, la constituyó el ejército, bajo dominio de Pinochet; la segunda, los partidos politicos de derecha, quienes tenían un respaldo electoral no menos importante; y tercero, los gremios empresariales, que formaron una comunidad de intereses económicos y políticos sin fisuras (Cortés Terzi, 2000).

En la Araucanía, los gobiernos de la década de los años noventa heredaron no sólo un modelo económico productivo consolidado, sino que también las contradicciones sociales y demandas históricamente postergadas del pueblo mapuche. La relación gobiernos de la concertación en la región se encuentra marcada por tres momentos claramente diferenciables. El primero, desde el Acuerdo de Nueva Imperial en diciembre de 1989 hasta la dictación en octubre de 1993 de la Ley Indígena $\mathrm{N}^{\circ}$ 19.253, que estableció las normas de protección, fomento y desarrollo indígenas creando la Corporación Nacional de Desarrollo Indígena (CONADI). Los resultados fueron decepcionantes para la dirigencia Mapuche, que consideró que sus demandas y propuestas no se encontraban incorporadas plenamente en la nueva institucionalidad (Bengoa: 1996).

Un segundo momento correspondió al gobierno de Eduardo Frei. En esta segunda administración post dictadura, la decisión fue de preservar el sistema económico desarrollando lo que algunos estudios han denominado una fase de modernización económica sin modernización política (Huneeus, 2014). La construcción de la Central Hidroeléctrica de Endesa en Ralco constituyó un claro hito a nivel regional del necesario esfuerzo modernizador que el país debía acometer, puesto que de acuerdo con los logros económicos del momento (en 1994 la economía creció por encima del 7\% anual) nos encontrábamos en el umbral de desarrollo. Finalmente, un tercer momento estuvo eclipsado por la "Política de Nuevo Trato" impulsada por el gobierno de Ricardo lagos, mediante la cual se prometió focalizar su accionar en torno a tres ejes: derechos de los pueblos indígenas, desarrollo con identidad y adecuación del Estado a la diversidad cultural. Si bien los anuncios parecieron contundentes, el accionar del gobierno estuvo marcado por grandes contradicciones, donde lo retórico quedó subordinado a lo práctico. En definitiva, su administración no introdujo las reformas jurídicas ni políticas que fueron propuestas por la "Comisión Verdad Histórica y Nuevo Trato" (CVHNT) y por las entidades internacionales. Por el contrario, quedaron pendientes el reconocimiento constitucional al pueblo mapuche, la ratificación del Convenio $N^{\circ} 169$ de la Organización Internacional del Trabajo (OIT), sobre 


\section{Exclusión y politización: Trayectoria económica y política de los durante el siglo $\mathrm{XX}$}

Pueblos Indígenas y Tribales en Países Independientes. Existe consenso en señalar que este mandato se aplicó una "estrategia dual hacia los pueblos indígenas", que combinó (sin acierto) una política sectorial orientada a beneficiar con tierras y recursos para el desarrollo material y cultural a quienes no cuestionaran las opciones del modelo de desarrollo y otra de carácter represivo, manifestada en el tratamiento criminal de la protesta social indígena, en el uso de la legislación especial que incluyó la Ley Antiterrorista para enfrentarla (Yánez y Aylwin, 2007; Pairican, 2014).

En definitiva, Ricardo Lagos buscó tempranamente la confianza de los empresarios e inició una interlocución con los grandes capitales del país a través del Centro de Estudios Públicos (CEP), controladora de la CMPC, colocando el crecimiento económico como principal objetivo. Para asegurar la marcha de los negocios resultaba indispensable suspender cualquier otra consideración de carácter social. Con elocuencia uno de sus asesores en el mítico segundo piso en La Moneda, Ernesto Ottone, resumía con claridad el principio rector de la administración: "Sin crecimiento no hay empleo, porque sin crecimiento no hay recursos para la inversión en equidad, porque sin crecimiento no hay progreso" (Ottone y Vergara, 2006).

En el escenario que describimos, los sectores empresariales identificados con los gremios agrícolas tradicionales y forestales transnacionales de la región asumieron tareas y estrategias de acción politica diferenciadas para enfrentar la profundización de la matriz productiva neoliberal. Un ejemplo de lo anterior se verificó con ocasión del proceso de internacionalización de la economía chilena con el retorno de los gobiernos democráticos en los años noventa. En este contexto, una fisura interesante de observar se provocó entre la Sociedad Nacional de Agricultura (SNA) y el CAS como resultado de los anuncios de integración que el gobierno de Eduardo Frei promovía con el Asia Pacífico, Europa, el Mercado Común del Sur (MERCOSUR) y otras regiones del mundo. Mientras la agricultura tradicional de los pequeños y medianos empresarios del sur demandó mayor protección frente a los potenciales efectos de las importaciones, la SNA mantuvo una postura favorable al libre mercado y cercana a las conveniencias de otros sectores productivos controlados por el gran empresariado nacional (Avendaño y Escudero, 2016). De manera similar a las movilizaciones del periodo 1977 y 1983, los agricultores tradicionales manifestaron su rechazo y se movilizaron activamente. El momento más emblemático de las movilizaciones en contra de los tratados de libre comercio se produjo en julio de 1995 con la convocatoria a una concentración de los agricultores en la medialuna de San Carlos, provincia de Ñuble, donde se congregaron más de 25 mil pequeños y medianos empresarios agrícolas. El resultado concreto fue que las protestas generaron un cambio en las negociaciones del resto de los tratados de libre comercio, mejorando las condiciones para la agricultura nacional rubro por rubro (Scapini, 2006). A1 
cumplirse 15 años de la firma del acuerdo del Mercosur, el presidente del Consorcio Agrícola del Sur (CAS), Gastón Caminondo, consideró que el sector de la agricultura tradicional sustitutiva de importaciones en las regiones no tenía nada que celebrar, manifestando que: “(para) nosotros es una fecha que nos produce, sino enojo, algo muy parecido a ello". Asimismo, agregó que "... lo único que pedimos es que todos juguemos con las mismas reglas, que les pidamos a otros, lo mismo que nos piden a nosotros. Y que esas reglas sean respetadas"6.

La intensificación de la movilización mapuche en las regiones del Biobío y la Araucanía desde 1997 fue un tema de debate ineludible para las asociaciones empresariales. Ciertamente, las ocupaciones de tierras trajeron a la memoria colectiva del conjunto de los empresarios los acontecimientos previos a septiembre de 1973, confirmando que la naturaleza social y política de muchos eventos de la década de los sesenta y setenta se mantenían activos en el recuerdo de los agricultores (Manzi, 2003). De esta manera, fueron los agricultores tradicionales y los gremios representativos del sector quienes reaccionaron activamente frente a lo que consideraron "hechos vandálicos" que violaban la propiedad privada. Utilizando profusamente los medios de comunicación, se encargaron de denunciar la intensificación del conflicto territorial, marcando en muchas ocasiones la agenda política regional y nacional.

El año 1999 fue definida por las comunidades Mapuche como "El año de la Rebelión". En este contexto, el volumen y complejidad del conflicto es tan amplio que resulta dificil dar cuenta de todos los acontecimientos acaecidos en las regiones del Biobío, la Araucanía y Los Lagos. Entre los hechos más relevantes podemos destacar la ocupación del Fundo Santa Ema, propiedad de Forestal Mininco por las comunidades lideradas por Víctor Ancalaf (La Tercera. 4 de febrero de 1999). Este dirigente ha retomado las recuperaciones de tierras durante el último tiempo que se suma a una movilización más amplia del movimiento mapuche ante las promesas incumplidas por el gobierno y la situación pandémica (El Mercurio: 16 de agosto: C7)

Por su parte, unas treinta familias mapuches de diversas comunidades aledañas al sector Lautaro-Antiquina, ocuparon un predio, propiedad Forestal Arauco (La Tercera. 12 de marzo de 1999). En el mes de abril, un centenar comuneros mapuche-pehuenches de las comunidades Manuel Marillanca y Quintonahuel ocuparon un fundo a cargo de la CONAF en sector de Reigolil, a

6 "El juicio del agro a los 15 años del Mercosur". Disponible en: http://agrostart.blogspot.com/2011/06/el-juicio-del-agro-los-15-anos-del.html 


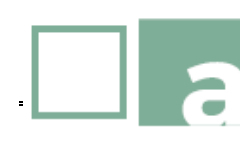

\section{Exclusión y politización: Trayectoria económica y política de los durante el siglo $\mathrm{XX}$}

cuatro kilómetros de Curarrehue (La Tercera. 23 de abril de1999). Adicionalmente, 78 familias de la comunidad de Llafenco se instalaron en terrenos de propiedad de la empresa Sociedad Agrícola Forestal Oregón en el sector oriente de Pucón. Un número cercano a cien mapuches de las comunidades de Colihuinca Tori y Antonio Paillacón (agrupados por la Coordinadora Arauco Malleco) ocuparon la Hacienda Rucañanco, propiedad de Forestal Mininco, mientras que comuneros de Tranicura ingresaron a un predio de Forestal Volterra, al sur de la comuna de Tirúa, y Miembros de la comunidad José María Calbún se tomaron 90 hectáreas en poder de un particular. (Diario el Sur. 27 de abril de 1999; La Tercera. 27 de abril 1999).

Quizás el hecho más relevante fue la ocupación de la hacienda Lleu Lleu por parte de la comunidad Pascual Coña, que en el mes mayo fue afectada por incendio aparentemente intencional y que destruyó un galpón, maquinaria e insumos agrícolas. Para el werken José Huenchunao, las acciones responden a la necesidad y pobreza de muchas comunidades indigenas, que están ingresando a los predios para sembrar cereales o para cosechar bosques, destacando que "... El Gobierno no da señales de querer devolver los predios en conflictos, por lo que la gente se moviliza por necesidad...". (La Nación Crónica. 28 de abril de 1999).

La respuesta del mundo empresarial frente a las movilizaciones no se hizo esperar. Jorge Serón, presidente regional de la Corporación Chilena de la madera (Corma) señaló que “... el Gobierno debe garantizar la tranquilidad y el Estado de derecho". Por su parte, Hernán Ascuí, presidente de la Cámara de la Producción y del Comercio, dijo que "... la violencia no contribuye a fomentar nuevas fuentes de trabajo...". Desde Santiago, las grandes asociaciones empresariales asumieron una posición cada vez más crítica y contestataria al movimiento mapuche. En este sentido exigen que el gobierno termine, a través de la fuerza, con un conflicto que les está causando pérdidas millonarias. Walter Riesco, presidente de la Confederación de la Producción y del Comercio (CPC), manifestó que

nadie puede comprender que en hechos de tanta gravedad y con niveles de violencia tan inusitados, finalmente nadie resulte procesado. Esa es una pésima señal, especialmente en momentos en que la ciudadanía exige mano dura en el combate de la acción criminal que nos afecta como país (La Tercera. 2 de marzo de1999).

Por su parte, el presidente de la SNA, Ricardo Ariztía, señaló en tono de alarma que "... hay activistas de la etnia mapuche que se aprovechan de la pobreza del sector y han comenzado una verdadera usurpación de tierras... el Gobierno debe encontrar una solución y no sólo bajarle el perfil al problema". (La Nación Crónica. 28 de abril de 1999). 
Años después Héctor Llaitul respondería a estas acusaciones.

Argumentaba sobre la inexistencia de grupos paramilitares en la zona en conflicto. En una de las primeras declaraciones públicas señalaba la necesidad de operar con medidas de seguridad debido a la existencia de grupos organizados por las forestales para amedrentarlos como dirigentes. Es evidente que para comprender a cabalidad el escalonamiento de la violencia en el conflicto es consecuencia de la ausencia de una solución política integral que derivaría pocos años después a intentar dar una solución en el marco del Estado de Derecho con la Comisión de Verdad Histórica y Nuevo Trato. (Llaitul y Arrate, 2012).

En reacción a las presiones empresariales, el gobierno intentó enviar una señal a la opinión pública de control en las zonas en conflicto. De esta forma, el Ministro Secretario General de la Presidencia, John Biehl, aseguró que el gobierno aplicaría todo el rigor de la ley a quienes promuevan el uso de la violencia, en la circunstancia que sea. Por su parte el Subsecretario del Interior, Guillermo Pickering, aseguró que las minorías violentistas tendrían una drástica sanción y después amenazó, en más de una ocasión, con aplicar la "Ley de Seguridad Interior del Estado" (La Tercera. 15 de mayo de 1999; Diario el Sur. 26 de mayo de 1999). Frente al aumento de las movilizaciones, el Ejecutivo amenazó con no negociar con quienes estuviesen movilizados. E1 ministro del Interior, Raúl Troncoso Castillo, en esa misma línea argumental señaló_ "el gobierno quiere ser claro en señalar que el camino de las tomas no es adecuado para resolver el problema y que el gobierno no aceptará sentirse presionado ni dejarse presionar cuando se efectúan tomas de predios" (Diario el Sur. 29 de abril de 1999). De igual forma Germán Quintana declaró que "no negociaremos si ponen una pistola sobre la mesa" (La Tercera. 6 de mayo de 1999).

Al finalizar el año de la "rebelión Mapuche", Ricardo Ariztía, señaló que “... lisa y llanamente estamos frente a una situación que pasa a ser un conflicto nacional y en este sentido, el gobierno tiene la obligación de abordarlo como una política de Estado". (Pairican, 2016). Asimismo, Ariztía comenzó a referirse al movimiento mapuche como "terrorismo rural" (Pairican, 2016). No es extraña la interpelación Ariztía y su lenguaje provocador. Haciendo gala de un carácter fuerte y hostil a la hora de defender los intereses del empresariado, como presidente de la CPC hizo fama de sus mensajes directos a las autoridades. Por ejemplo, en el encuentro ENADE del 2001 se dirigió al presidente Ricardo Lagos señalando: “... por favor, déjenos trabajar tranquilos” (E1 Mercurio, 25 de julio de 2004). 


\section{Exclusión y politización: Trayectoria económica y política de los durante el siglo $\mathrm{XX}$}

En el contexto de los focos de tensión social ocasionada por el conflicto territorial, las empresas forestales desarrollaron acciones que definieron como "acciones de buena vecindad". Como indica Noelia Carrasco, las empresas forestales comenzaron un proceso de reconocimiento formal de las condiciones de pobreza y exclusión en que efectivamente se encuentran sus "vecinos mapuche" (Carrasco, 2012). Se inicia así el año 2008 una política de "Responsabilidad Social Empresarial" (RSE) en las relaciones entre empresas forestales y comunidades mapuche. Un caso emblemático fue el que se desarrolló entre la empresa Forestal Mininco, perteneciente al grupo CMPC, y la comunidad Tricauco, quienes reclamaban derechos sobre aproximadamente 50 hectáreas de bosque de pino. Los resultados se orientaron a mitigar los conflictos de la empresa y las comunidades mapuches mediante el establecimiento de relaciones de confianza (Wigodski, 2007). Desde una perspectiva crítica, Héctor Nahuelpan, sostiene que la estrategia empresarial de "buena vecindad" respondió a una iniciativa asistencialista planificada para cooptar y desmovilizar las demandas mapuches y que hemos situado dentro de la estrategia de multiculturalismo como opción para reencauzar dentro del liberalismo económico y político la situación mapuche lo que podría generar diferencias internas al interior de los mapuche y nuevos tipos de diferencias sociales. Es viable observar que ante la apuesta multicultural se pueda desarrollar diferencias sociales entre grupos indigenas (Nahuelpan, 2016 y Pairican, 2018).

Durante los años 2003 hasta el 2010, nuevas organizaciones políticas mapuches emergieron con el objetivo de profundizar en la dimensión política del conflicto; es decir, avanzar en la reformulación de la Constitución para el reconocimiento de los pueblos indígenas (Pairican, 2018). El año 2008 fue un nuevo momento en la intensificación de la reivindicación Mapuche y, al mismo tiempo, la agudización de la represión policial. El 3 de enero, la opinión pública nacional conoció el asesinato del joven Matías Catrileo Quezada, asesinado por la espalda por el cabo segundo de Carabineros, Walter Ramírez, durante la ocupación del Fundo Santa Margarita. El 31 de ese mismo mes, fallece Johny Cariqueo, con 22 años, como consecuencia de la golpiza proporcionada por Carabineros en un cuartel policial.

En este escenario, los Think Tank privados vinculados a la derecha y el sector empresarial desplegaron una arremetida comunicacional que cuestionó el diseño y políticas de entrega de tierras a las comunidades Mapuche por parte de la CONADI. A través de columnas de opinión en los principales medios destacaron que el balance de dichas estrategias condujeron a una política pública ruralizante y la segregación de las comunidades indígenas, a lo que se suma a la ausencia de programas eficientes de producción, por lo que las comunidades no logran salir de la pobreza (Ena von Baer, Instituto Libertad y Desarrollo, El Mercurio, Cuerpo A, 16 de agosto de 2009). En la columna de 
opinión “Tierra por paz, ¿es esto justo?”, Beatriz Corbo, investigadora

Fundación Jaime Guzmán, consideró que la "politica indigena... ha sido deficiente, pues se ha recurrido a la entrega de tierras sin entrar al fondo del problema". Agregó, además, que estas políticas han "olvidado que la gran mayoria de los indigenas chilenos viven hoy en las ciudades y hacia ellos no se han focalizado recursos". En consonancia con la visión empresarial, la experta en temas indígenas abogó por una política que implementase,

mecanismos que hagan viable la explotación de las tierras entregadas, con miras a lograr que la integración al proceso de desarrollo y la preservación de la identidad de las culturas indígenas sean perfectamente compatibles levantando esa verdadera interdicción que pesa sobre las comunidades indigenas para disponer de sus tierras (El Mercurio, Cuerpo D, 13 de julio de 2008).

Desde el punto de vista de las organizaciones gremiales de la región las movilizaciones mapuche consistían en un "conflicto político" con el Estado, eludiendo la responsabilidad de las fuerzas de la producción en este proceso. En este sentido, a través de una crónica publicada por El Mercurio, los empresarios de la región señalaron que la serie de atentados e incendios, que han recibido sus propiedades, retrata la acción de grupos catalogados como "terroristas que se aprovechan de la pobreza de ciertos sectores de la región". En este sentido, el contenido de la crónica destacó cómo los empresarios "trabajan codo a codo con las comunidades mapuches cerca de sus predios $e$ industrias", y que es un porcentaje minimo el de mapuches comprometidos en acciones de violencia. En consonancia con la opinión de los expertos de los Think Tank de la derecha, los episodios de "violencia Mapuche" son adjudicados a la entrega de tierras, pues los fundos tomados son comprados por la CONADI para distribuir las tierras a las comunidades. Por tanto, las acciones reivindicativas corresponden a grupos minoritarios, que buscan de manera artificial y violenta imponer sus demandas. (E1 Mercurio, Cuerpo B, 13 de enero de 2008).

Durante esta etapa, el discurso empresarial y de los sectores de la derecha política resulto invariable. En este sentido, de manera consistente a través de los medios de comunicación y en declaraciones públicas se homologó la protesta social mapuche por el reconocimiento político con actos de "violencia terrorista" que atentaban contra el progreso económico y la paz social. Un ejemplo de lo que comentamos se encuentra en una crónica de El Mercurio, que recogiendo las demandas de los gremios empresariales de la región hacía un llamado al primer gobierno de Michelle Bachelet para que asumiera “... su responsabilidad constitucional de garantizar la plena vigencia del Estado de Derecho", exigiendo, además, que se restableciera la seguridad y el orden 


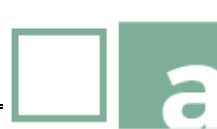

Exclusión y politización: Trayectoria económica y politica de los durante el siglo $\mathrm{XX}$

público en la zona para terminar con la "impunidad de los grupos terroristas" (El Mercurio, Cuerpo C, 19 de agosto de 2008).

Al finalizar la primera década del siglo XXI, las organizaciones gremiales de la agricultura tradicional de la región insistieron sobre dos temáticas de recurrente preocupación para el desempeño de sus unidades productivas: el tipo de cambio del dólar producto de los acuerdos internacionales y, en segundo lugar, el conflicto mapuche en la zona de la Araucanía. Ambas dimensiones definieron la agenda del sector durante el primer gobierno de Michelle Bachelet. Con ocasión del encuentro Enagro 2008, el presidente de la SNA, Luis Schmidt Montes, manifestó que,

No puedo dejar de mencionar lo clave que resulta trabajar en un ambiente de paz y entendimiento. Lamentamos los incidentes que han ocurrido en las zonas rurales del sur de nuestro pais, donde grupos violentistas, arrogándose la representación del pueblo mapuche, violan los derechos básicos de honestos hombres de campo. Tal como lo difundió hace unos días un estudio en esta materia, estos hechos desalientan las inversiones y sumen a las familias de esos territorios en un mundo de desesperanza y destierro. ¡Ellos no se lo merecen! ¡Chile, tampoco! (Discurso de Luis Schmidt Montes, presidente de la SNA, Enagro 6 de octubre de 2008)

Las razones de esta preocupación surgen del hecho que una vez más el crecimiento económico y las esperanzas en el buen rumbo de los negocios se encuentran basados en la exportación de bienes primarios con escaso valor agregado y condicionados al término del conflicto territorial mapuche.

\section{Proyecciones del conflicto social y politico del pueblo mapuche.}

El movimiento mapuche ha usado frente al Estado chileno distintas estrategias politicas para mantener su autonomía y proyectarse como pueblo. (Marimán, 1997; Boccara y Seguel, 2005). En un primer momento, predominó la concepción que alentó la asimilación de las "etnias", bajo el supuesto que la cultura dominante era superior y, por lo tanto, debía substituir a las culturas inferiores. En el siglo XX se perfiló una estrategia integracionista en la que se aceptó la idea que la nacionalidad era el producto de una fusión de razas, aunque los mapuches defendieron la permanencia de algunos valores culturales (Marimán et al., 2006). No obstante, ese ciclo agotado a mediados de los 60', dio paso a que los mapuche usaran las corridas de cerco para obtener sus anhelos de tierras y en algunos sectores su emancipación. Algo de ese debate fue comprendido por la Unidad Popular en la promulgación de una Ley Indígena que no logró aplicarse, no obstante, la corrida de cercos y el parlamento fueron los dos mecanismos usados por los mapuche para recuperar sus territorios y retomar espacios de poder. 
El golpe de Estado, el exilio de algunos mapuche y los conflictos internacionales marcaron la política en el pueblo mapuche. Estas tres variables más su propia historia marcada por la ocupación y el primer ciclo de movimiento organizacional influyeron en la gestación durante la segunda mitad de la década de 1990 de un movimiento autonomista. Este movimiento tiene sus raices en una historia que comienza en 1910, que se ve impactada por la Reforma Agraria y el contexto de indigenismo internacional. Pero que no olvida la memoria de la Ocupación de La Araucanía. Estas tres variables sitúan hacia 1979 la necesidad de crear un nuevo tipo de organización politica que piensa la Autonomía. Esta organización se denominó Ad Mapu, desde la cual emerge luego el Aukiñ Wallmapu Ngulam y también algunos de los miembros que fundarían la Coordinadora Arauco Malleco. Estas dos últimas organizaciones consolidaron la autonomía como opción. No existían espacios de convergencia con el Estado chileno, derechamente declararon que el camino para el pueblo mapuche sería la Liberación Nacional (Parican: 2014).

E1 Estado chileno respondió con la creación de una Ley Indígena promulgada en 1993. A través de ella se permitió la incorporación de los mapuche al sistema educativo forjando una suerte de clase media mapuche. También se desarrollaron proyectos para fomentar la producción e inserción de los mapuche al campo profesional técnico. Menos avances se dieron en materias de derechos colectivos, la Ley Indigena fue una normativa de fomento y desarrollo de la identidad, pero sin derechos políticos. No es que estos quedaron exentos del debate, no pudieron llevarse a efecto por la presión ejercida por algunos parlamentarios de la derecha que se negaron a avanzar en los acuerdos de Nueva Imperial (Bengoa, 2000).

Una de las raíces del actual desencuentro se encuentra en las promesas incumplidas de Nueva Imperial en 1989. Aquel 1 de diciembre de 1989, el candidato presidencial Patricio Aylwin se comprometió a cumplir las demandas indígenas de elaboración de un marco jurídico a favor del desarrollo de los pueblos originarios, si triunfaba en las elecciones presidenciales, reconocería constitucionalmente a los pueblos originarios y ratificaría el Convenio 169 de la Organización Internacional de Trabajo (OIT) (E1 desconcierto, 24 de septiembre de 2018)7.

Las politicas de reconocimiento de los gobiernos de la Concertación no fueron acompañadas por las Reformas políticas entorno a los derechos colectivos debatidos en ese momento a nivel internacional que concluyeron en 2007 en

7 Véase: https://www.eldesconcierto.cl/2018/09/24/de-aylwin-a-pinera-el-historial-de-laincumplida-promesa-del-reconocimiento-constitucional-al-pueblo-mapuche/. Revisado el 16.08.2020. 


\section{Exclusión y politización: Trayectoria económica y política de los durante el siglo $\mathrm{XX}$}

la Declaración de la ONU sobre los derechos indígenas. Bajo ese escenario las insurrecciones del Ejercito Zapatista de Liberación Nacional y el movimiento Katarista en Bolivia que luego terminaría con el triunfo de Evo Morales en la presidencia del año 2006 cambiaron el contexto latinoamericano y también la discusión en el movimiento mapuche.

La situación internacional en materias de derechos indigenas generó un debate al interior del mismo movimiento. Mientras que un sector decidió continuar con la Autodeterminación vía Control Territorial asumiendo las recuperaciones de tierras con el uso de la violencia como instrumento, el triunfo de Morales abrió un camino dentro de la institucionalidad para la conquista de los derechos colectivos. Este fue el caso adoptado por Adolfo Millabur, alcalde de Tirúa que asumió el camino institucional y que, en el año 2010, tendría un complemento al fundarse el Partido Mapuche Wallmapuwen. Frente a la situación política del tiempo presente, Millabur ha planteado la Plurinacionalidad con perspectiva Intercultural como uno de los caminos posibles para avanzar en los derechos colectivos, en sus palabras:

¿La plurinacionalidad como una vía? Por la experiencia que uno ha recogido con los paises vecinos, en este caso Ecuador y Bolivia. He tenido la oportunidad de conocer bastante de cerca los dos procesos, uno más que otro; Ecuador más que Bolivia. Creo que a partir de ese concepto se permite generar una especie de convergencia para dialogar. Es importante que haya una convergencia porque si yo le hablo a la sociedad chilena desde que reivindico la autonomía, los pones a la defensiva y yo desde mi trinchera. Lo veo como un concepto para poder entendernos y encontrarnos políticamente con el otro que no es mapuche, que no es de los pueblos originarios. A partir de ese punto de discusión, hablemos (Pairican, Millabur, y otros: 2020: p. 181).

Para Adolfo Millabur, integrante de la Identidad Territorial Lafquenche y representante de la "vía política" a la Autonomía, lo expuesto permitiría correr "el cerco de lo posible". Metáfora que hace alusión a la corrida de cercos de la Reforma Agraria que conoció como niño junto a sus antepasados y a su vez, la vía gradualista que caracteriza a Chile, a la hora de tomar opción por un camino de transformación.

En perspectiva histórica, la representación indígena en general, y la mapuche en particular, se ha realizado mediante partidos e instituciones chilenas, y ha relegado lo mapuche y a sus líderes a una posición subordinada que no permite una participación eficiente en las decisiones con respecto a la agenda étnica (Tricot y Bidegain, 2020). En el siglo XX, la Sociedad Caupolicán optó por crear un partido mapuche el año 1932 y la Corporación Araucana desarrolló una estrategia político-electoral y de alianzas (Ancan, 2010). Otro caso para destacar fue el Partido de la Tierra y de la Identidad de 1989 y que no logró constituirse como partido político reconocido. 
Por tanto, la emergencia de una "vía política" a la autonomía, lejos de estar ausente de tensiones con la "vía rupturista", se suma al repertorio de acción colectiva mapuche (Pairican: 2013). Sin embargo, como proclamó Aucan Huilcaman, dirigente del Consejo de Todas las Tierras, la experiencia reproduciria un colonialismo interno. Por su parte, inicialmente la Coordinadora Arauko Malleco (CAM) fue critica al Wallmapuwen, considerándola como una construcción del mundo intelectual mapuche cuyo objetivo sería captar apoyo electoral y obtener cargos, siendo ésta un camino inviable para conquistar los derechos de autodeterminación. Recientemente, el vocero de la organización, Héctor Llaitul, ha sugerido que como CAM no comparten esta forma de participación, pero que la encuentran legítima como una forma más de lucha del pueblo mapuche (Tricot y Bidegain, 2020). Con todo, el Partido Mapuche Wallmapuwen, con una trayectoria de 10 años, es un camino complementario y divergente a la lucha social y político Mapuche y se posiciona como uno de los movimientos importantes post transición democrática (Pairican: 2014).

¿Cuál ha sido la respuesta del Estado de Chile frente al movimiento Mapuche durante los últimos 16 años? El camino que trazaron los gobiernos Bachelet y Piñera fue apostar por el multiculturalismo como manera de abordar la situación mapuche. Esta estrategia se suscribe a cómo el capitalismo incorpora a los movimientos indígenas en base a sus lógicas económicas y la flexibilidad del modelo liberal. Durante el gobierno de Michelle Bachelet se planteó explícitamente esta política al denominarla: Reconocer: pacto por la multiculturalidad. El gobierno de Sebastián Piñera profundizó esa arista en un sentido neoliberal, para luego continuar la senda entorno a una política de consultas indígenas intentando llevar a la praxis el Convenio 169 de la OIT.

De esta manera, podemos incluso observar a algunos líderes Mapuche que, al interior de los partidos chilenos, fuerzan a tomar una definición en pos de los derechos fundamentales. No obstante es una tensión que no ha dejado de generar controversias al interior del mismo movimiento mapuche. Mientras algunos comparten el camino de la Plurinacionalidad "desde arriba"; otros han optado, a partir de los cargos aceptados por algunos miembros de la corporación mapuche ENAMA en el actual gobierno, que la vía multicultural como opción política.

No obstante, el movimiento mapuche continúo profundizando su quehacer político y en la medida que los gobiernos optaron por el multiculturalismo, los mapuche radicalizaron su accionar fundando nuevas organizaciones autonomistas que usaron la violencia política como instrumento. En La Araucanía nació en 2012 la organización Aukan Weichan Mapu y en la provincia de Arauco la Resistencia Territorial Arauco. Ambas organizaciones 


\section{Exclusión y politización: Trayectoria económica y política de los durante el siglo $\mathrm{XX}$}

son las que hoy han reivindicado a lo menos una treintena de hechos de violencia política como quema de camiones y enfrentamientos con la policía durante el año en curso.

Cabe destacar que la vía de la Plurinacionalidad ha sido la fórmula adoptada por algunos Estados. En Ecuador, por ejemplo, se definió un "Estado constitucional de derechos y justicia, social, democrático, soberano, independiente, unitario, intercultural, plurinacional y laico". En Bolivia se adoptó un "Estado Unitario Social de Derecho Plurinacional Comunitario, libre, independiente, soberano, democrático, intercultural, descentralizado y con autonomias", que está relacionado con el reconocimiento de la preexistencia de las naciones y pueblos originarios. El senador Francisco Huenchumilla considera este Estado Plurinacional como un paso al reconocimiento de los pueblos originarios como actores y sujetos de derechos colectivos, para ser incorporados en base a una nueva estructura del Estado, a nivel constitucional. La organización del Estado Plurinacional sería la república y se gobernaria de manera descentralizada (Huenchumilla, 2016). En esta perspectiva, las organizaciones que han ocupado la vía institucional como camino para desmantelar la república homogénea, han sido en esta línea las organizaciones como las Identidades Territoriales, la Asociación de Alcaldes Mapuche y Wallmapuwen. Las dos primeras organizaciones sí observan en la Plurinacionalidad una posibilidad.

Es cierto que el Estado Plurinacional puede "domesticar" los derechos, como ha sostenido Aucan Huilcaman en su encuentro en la cumbre del cerro Ñielol (CiperChile, 20 de diciembre de 2019). Para este dirigente, que ha planteado la Autodeterminación como sendero para la liberación de Wallmapu, el Estado Plurinacional es un "parteaguas" en el ascenso de la autodeterminación, e impondría una nueva institucionalidad chilena que no empoderaría a la sociedad mapuche. Por el contrario, la dominación se revigorizaría a partir de institucionalidades criollas administradas por funcionarios mapuche (Pairican, Millabur y otros: 2020).

Considerando todo este debate, el Estado Plurinacional, de todos modos, podría inaugurar una vía "mapuche" a la autodeterminación al interior de un país donde el colonialismo goza de buena salud, sea por la capacidad de regenerarse y también por la incapacidad del movimiento mapuche en desmantelarlo. En ese ámbito el Estado Plurinacional puede servir para remover las estructuras de dominación en las tomas de decisiones en los planos económicos y políticos.

A favor del movimiento autodeterminista, existen experiencias de Control Territorial que da cuenta de lo viable de la alternativa impulsada por los sectores rupturistas del movimiento en algunas zonas de Arauco, Ercilla y 
Vilcún. En el transcurso del año 2001-2003, la Coordinadora Arauco

Malleco lo definió como un proceso de mediana duración en que se irían conquistando predios como bases de la autodeterminación. En ese ámbito, en la medida que se avanza en el proceso, su construcción política se enmarcaría como parte de la lucha contra el modelo capitalista y por lo tanto, en una alternativa política para crear un nuevo tipo de sociedad comunitaria. Dialécticamente, en la perspectiva de la CAM, sería una estrategia, un paso intermedio, para reconstruir el Wallmapu desde abajo. El Control Territorial por lo tanto disputa el territorio, recrea el hábitat del Buen Vivir, se opone a la jerarquía del Estado chileno y consolidaría la autonomía disputando el territorio y liberándolo para el retorno de los habitantes mapuche que viven en la diáspora política. Todo este proceso culminaría con la reconstrucción del Wallmapu (CAM, 2019).

\section{Conclusión}

La trayectoria de historia económica y politica regional, con sus avances, dificultades y exclusión, pueden ser situados desde una perspectiva de larga duración; enfoque que permite una mejor comprensión de los desafios pendientes. Este es un tema central, pues las relaciones entre los sectores público, privado y el movimiento mapuche en el siglo XX no se agotan en su obvia importancia, sino que en el desocultamiento del papel e intereses que correspondió desempeñar a cada uno de los actores sociales.

Desde el punto de vista de la economía politica regional, los desafios pendientes dicen relación con la capacidad de los actores Mapuche para pensar una estrategia de desarrollo económico -o de modernización- que hasta el momento se encuentra pendiente, o mejor dicho, ausente. Como anticipáramos, la incorporación tardía de la región al estado Nación chileno mediante la ocupación militar setenta años después del nacimiento del nacimiento como república independiente - definió en gran medida el devenir económico subordinado de la macrozona a las lógicas de expansión productiva sin transformaciones estructurales.

Paradojalmente, los cambios trascendentales en 1965 y 1973 en la región abrieron paso, de forma impensada, a los problemas del actual modelo de desarrollo en la región y la rearticulación del movimiento mapuche con una nueva comprensión de las condiciones estructurales de la exclusión y las nuevas estrategias políticas a favor de la autonomía y proyección como pueblo nación Mapuche. La reforma agraria cristalizó un movimiento por las corridas de cerco para obtener sus anhelos de tierras y en algunos sectores su

\section{anuario.}




\section{Exclusión y politización: Trayectoria económica y política de los durante el siglo $\mathrm{XX}$}

emancipación. Algo que la Unidad Popular comprendió con la promulgación de una Ley Indígena que no logró aplicarse.

Por otra parte, los éxitos de la política extractivita del actual modelo neoliberal en la región se encuentran asociados a los cambios trascendentales ocurridos en esta misma fase. En efecto, tanto el gobierno de Eduardo Frei como el de Salvador Allende tuvieron el mérito de destrabar los bloqueos estructurales en una región que había basado su estrategia de desarrollo bajó prácticas productivas y laborales de "antiguo régimen". Esos cambios estructurales hicieron más fácil la tarea transformadora que desempeñaron los Chicago Boys. La reforma agraria, las expropiaciones industriales, los programas de fomento frutícola $\mathrm{y}$ forestal fueron decisivos para el crecimiento de las exportaciones en la década de 1980. A lo anterior, esta matriz de desarrollo agregó otro componente necesario en la región: la exclusión y despojo territorial de las comunidades mapuches.

En un momento en que el país se encuentra avanzando hacia un momento constituyente. Como en pocas ocasiones, la posibilidad de desmantelar el republicanismo homogéneo ha develado la oportunidad de pensar en un nuevo tipo de Estado que aspire a que las naciones originarias sean portadoras y sujetos de derecho al interior de la democracia chilena. A lo largo de su historia, la república se ha encargado de negar sistemáticamente cualquier avance en la democratización y reconocimientos desde los marcos legales, coherente con una construcción de Estado y de sectores políticos que no respetan la diversidad ni tampoco los nuevos Derechos Humanos emanados de organismos internacionales.

Visto de esta manera, tanto los problemas del desarrollo, como los logros y dificultades recientes del movimiento Mapuche nos muestran que el nivel de los desafios es complejo. Tal como la construcción de un Estado-nación, la elaboración de un Estado Plurinacional es una tarea de largo aliento. En esta trayectoria el problema es cómo traducir adecuadamente las promesas y no quedar en el camino de los espejismos. Desde este punto de vista, este ensayo siguió la recomendación que determina que los historiadores no sólo tienen que habérselas con un número mayor de variables que los cientistas sociales y los economistas, sino también con elementos no mensurables, irracionales, imprevisibles y con asociaciones que cambian constantemente entre las variables (Cipolla, 1991). 


\section{Bibliografia}

Ahumada, J. (1958). En vez de la miseria. Santiago: Editorial del Pacífico S.A.

Almonacid, F. (2016). Neoliberalismo y crisis económica: políticas estatales, mercado y agricultores en Chile, 1973 - 1985. En Historia Crítica (62), Bogotá.

Alvarado Lincopi, C., y Antileo, E. (2020). Diarios mapuche 1935-1966. Escrituras y pensamientos bajo el colonialismo chileno del siglo XX. Santiago: Ediciones CHM.

Ancan, J. (2010). Negritud y cosmovisionismo mapuche frente al poder (neo) colonial. Apuntes preliminares para una reflexión (auto) crítica. En Oliva, E.; Stecher, L., y Zapata, C. (eds.), Aimé Césaire desde América Latina. Diálogos con el poeta de la negritud (pp. 201-229). Santiago de Chile: Ediciones Facultad de Filosofia y Humanidades - Universidad de Chile.

Ancan, J. (2010). Venancio Coñuepan Paillal: ñizol longko y líder político mapuche del siglo XX. Santiago: Editorial USACH.

Aniñir, D. (2000) Mapurbe. Venganza a raíz. Santiago: Ediciones Pehuén.

Arriagada, G. (2004). Los gremios empresariales y la politica. Santiago: LOM Ediciones.

Avendaño, O., y Escudero, M. C. (2016). Elitismo y poder gremial en la Sociedad Nacional de Agricultura (SNA). En Revista CS, (20): 37 - 74. Cali, Colombia: Facultad de Derecho y Ciencias Sociales, Universidad Icesi.

Barnaby Carter, D. (2017). Los terratenientes de Cautín: actores claves de la contrareforma. En Anales (12) Séptima Serie, Santiago.

Bengoa, J. (2000). Historia del pueblo mapuche, siglo XIX y XX. Santiago: Ediciones LOM.

Campero, G. (1984). Los gremios empresariales en el periodo 1970 - 1983: comportamiento sociopolítico y orientaciones ideológicas. Santiago: Instituto Latinoamericano de Estudios Transnacionales.

Carrasco H. N. (2012). Trayectoria de las relaciones entre empresas forestales y comunidades mapuche en Chile: Aportes para la reconstrucción etnográfica 
Exclusión y politización: Trayectoria económica y política de los durante el siglo $\mathrm{XX}$

del desarrollo económico en contextos interétnicos. Polis

(Santiago), 11(31), 355-371. https://dx.doi.org/10.4067/S071865682012000100019.

Cipolla, Carlos M. (1991). Entre la historia y la economia. Barcelona: Editorial Crítica.

Cortés Terzi, A. (2000). El circuito extrainstitucional del poder. Santiago: Ediciones Chile américa - Cesoc.

Correa, M., y Mella, E. (2012). Las razones del illkun/enojo. Memoriam despojo y criminalización en el territorio mapuche de Malleco. Santiago: Lom Ediciones.

De la Maza, F., De Cea, M., y Rubilar, G. (2018). Politicas indigenas y construcción de Estado desde lo local. Santiago: Ediciones Pehuén/CIIR.

De Jong, I. (2009). Armando y desarmando Confederación: el liderazgo de Calfucurá en el período de la organización nacional. Revista de Historia Quinto Sol, $\mathrm{Vol}^{\circ} 13$.

Flores Chávez, J. (2011). Territorio y economía al sur del río Biobío durante la primera mitad del siglo XX. En J. Pinto Rodríguez (ed.); Araucanía, siglos XIX y $X X$. Economía, migraciones y marginalidad. Osorno: Colección Investigadores. Editorial Universidad de Los Lagos.

Ffrench-Davis, R., y Stalling, B. (2001). Reformas, crecimiento y politicas sociales en Chile desde 1973. Santiago: Lom Ediciones.

Foerster G. R. (2008). Los procesos de constitución de la propiedad en la frontera norte de la Araucanía: sus efectos esperados y no esperados en el imaginario y en la estructura de poder. En Cuadernos de Historia $\mathrm{N}^{\circ} 28$, pp. 7 - 35. Departamento de Ciencias Históricas, Universidad de Chile.

Frene, C., y Núñez, M. (2010). Hacia un nuevo modelo forestal en Chile. En Revista Bosque Nativo (47): 25 - 35.

Gallego, L., y Padilla, A. (1978). Victoria, los inicios de una ciudad 1881-1900. Victoria.

Gárate Chateau, M. (2012). La revolución capitalista de Chile (1973 - 2003). Santiago: Ediciones Universidad Alberto Hurtado.

Gómez, J. (2009). Tierra, territorio y autonomía: La lucha política del movimiento social mapuche en la sociedad neoliberal chilena. En Revista Estudios, (22), Universidad de Costa Rica.

\section{anuario.}


Gómez, S. y Echeñique, J. (1988). La agricultura chilena. Las dos caras de la modernización. Santiago: Flacso.

Henriquez Jaramillo, L. (2013). Cinco décadas de transformaciones en La Araucanía rural. En Polis. Revista Latinoamericana, (34). URL: http:// journals.openedition.org/polis/8802.

Hilger, I. (2001). Infancia: vida y cultura mapuche. Santiago: Pehuén Editores.

Huenchumilla, F. (2016). Plurinacionalidad: el nuevo pacto. Santiago. Pehuén Editores.

Huneeus, C. (2014). La democracia semisoberana. Chile después de Pinochet. Santiago: Taurus - Historia.

Huneeus, C. (2016). El Régimen de Pinochet. Santiago: Sudamericana.

Inostroza, I. (1998). Etnografia mapuche del siglo XIX. Santiago: Editorial Centro de Investigaciones Diego Barros Arana (DIBAM).

Lechner, N. (1990). ¿Son compatibles modernidad y modernización? El desafio de la democracia Latinoamericana. Santiago: Flacso - Documento de Trabajo $\mathrm{N}^{\circ} 440$.

Lavín. J. (1987). Chile la revolución silenciosa. Santiago: Zig-Zag.

Llaitul, H., y Arrate, J. (2012). Weichan conversaciones con un weychafe en la prisión politica. Santiago: Ediciones CEIBO.

López, E. (2020). El programa económico y social de la UP: su aplicación y la respuesta de los gremios empresariales. En Os 50 anos da Unidade Popular no Chile: um balanço historiográfico. Brasil: Editora Fino Traço, Belo Horizonte, Minas Gerais (En prensa).

Lovera, P. (2018). El dificultoso camino a la neoliberalización: El caso de la Sociedad Nacional de Agricultura, 1983-1990. En Divergencia (10), Año 7.

Manzi, Jorge et al, (2003). El pasado que nos pesa: la memoria colectiva del 11 de septiembre de 1973. Revista de Ciencia Política, Volumen XXIII, Número 2, $177-214$.

Marichal, C. (1998). Historia de la deuda externa de América Latina. Madrid: Alianza Editorial. 


\section{Exclusión y politización: Trayectoria económica y política de los durante el siglo $\mathrm{XX}$}

Mariátegui, J.C. (2007). 7 ensayos de interpretación de la realidad peruana. Ayacucho: Fundación biblioteca Ayacucho.

Menard, A. (2013). Libro Diario del Presidente de la Federación Araucana Manuel Aburto Panguilef. Santiago: CoLibris.

Montero, C. (1997). La revolución empresarial chilena. Santiago: Cieplan/Dolmen Ediciones.

Moulian, T. (1997). Chile actual anatomía de un mito. Santiago: LOM Ediciones.

MIDEPLAN-INE (2001). Panorama económico y social. Santiago: Mideplan.

Naguil, V. (2016). De la raza a la nación, de la tierra al país. Comunitarismo y nacionalismo en el movimiento mapuche, 1910 - 2010. (Tesis doctoral). Barcelona: Universitat Autònoma de Barcelona.

Nahuelpan, H. (2016). Micropoliticas mapuche contra el despojo en el Chile neoliberal. La disputa por el lafkenmapu (territorio costero) en Mehuín. Izquierdas (30), Octubre: 89-123.

Nazer, R. (2013). Renovación de las élites empresariales en Chile. En Ossandón, J. y Tironi, E. (eds.); Adaptación. La empresa chilena después de Friedman. Santiago: Ediciones Universidad Diego Portales.

Ottone, E., y Vergara, C. (2006). Ampliando horizontes. Siete claves estratégicas del gobierno de Lagos. Santiago: Random House Mondadori.

Pairican, F. (marzo 2013). La historia reciente de las luchas en La Araucanía. Rutas mapuche hacia la autodeterminación. En Le Monde Diplomatique, 8-9.

Pairican, F. (2014). Malón. La rebelión del movimiento mapuche. Santiago: Pehuén Editores.

Pairican, F. (2016). La fortaleza amurallada donde no penetran los vientos de la transformación: la actuación política de la Sociedad Nacional de Agricultura en la cuestión mapuche (1997 - 2004). En P. Canales Tapia (ed.), Zuamgenolu. Pueblo mapuche en contexto de Estado nacional chileno, siglos XIX - XX. Santiago: Editorial Universidad de Santiago de Chile.

Pairican, F. (2018). Los gobiernos de la Concertación y su política indígena: el multiculturalismo. En Revista Anales (15), Séptima Serie.

Pairican, F. (2019). Toqui: la resistencia mapuche a la Ocupación de La Araucanía 1818-1862. (Tesis doctoral). Universidad de Santiago de Chile. 
Pairican F, Millabur Adolfo y otros (2020): Wallmapu. Ensayos sobre plurionacionalidad y nueva constitución. Pehuen Editores.

Pavez, J. (2008). Cartas mapuche: Siglo XIX. Santiago: Ocho libros - ColibrísFondo de Publicaciones Americanistas.

PNUD (1996). Desarrollo humano en Chile. Santiago: Programa de las Naciones Unidas para el Desarrollo.

Pinto Rodríguez, J. (2012). El conflicto Estado-Pueblo Mapuche, 1900-1960. En Universum $\mathrm{N}^{\circ} 27$, Vol. 1. Universidad de Talca.

Pinto Rodríguez, J. (2015). Conflictos étnicos, sociales y económicos. Araucanía 1900-2014. Santiago: Pehuén Editores S.A.

Pinto Rodríguez, J. (2015) Conflictos fronterizos en La Araucanía. Santiago: Ediciones UFRO.

Pinto Rodríguez, J. (2002). La formación del Estado y la nación, y el pueblo mapuche. De la inclusión a la exclusión. Santiago: Ediciones DIBAM.

Pinto Santa Cruz, A. (1959). Chile un caso de desarrollo frustrado. Santiago: Editorial Universitaria.

Ponce, J. (2020). Revuelta popular: cuando la "nueva" clase trabajadora se tomó las calles. Santiago: América en Movimiento Ediciones.

Ross, C. (2003). Poder, Mercado y Estado. Los bancos de Chile en el siglo XIX. Santiago: Lom Ediciones.

Scapini, J. C. (2016). Los gremios empresariales en Chile. Santiago: Tajamar Editores.

Salazar, G. y Pinto, J. (2002). Historia contemporánea de Chile III. La economía: mercados, empresarios y trabajadores. Santiago: LOM Ediciones.

Samaniego, A y Ruiz. C. (2007). Mentalidades y politicas Wingka: pueblo mapuche, entre golpe y golpe (De Ibáñez a Pinochet). Madrid: Consejo Superior de Investigaciones Científicas, Colección América.

Scully, T. R. (1992). Los partidos de centro y la evolución politica chilena. Santiago: CIEPLAN-Notre Dame.

Thompson, E.P. (1992). Costumbres en común. Ediciones Capitán Swing. 


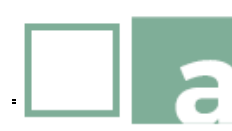

\section{Exclusión y politización: Trayectoria económica y politica de los} durante el siglo $X X$

Tricot, V., Bidagai, G. (2020). En busca de la representación politica: el partido mapuche Wallmapuwen en Chile. En Revista Estudios Sociológicos 38 (113).

Urrutia, M. (2019). El desalambre de los kuyfikeche. Una aproximación a las corridas de cerco en el Fundo Nehuentúe, 1971. (Tesis de licenciatura). Santiago: Universidad de Santiago de Chile.

Valdivia Ortiz de Zárate, V. (2008). Nacionales y gremialistas. El "parto" de la nueva derecha politica chilena, 1964-1973. Santiago: LOM Ediciones.

Widodski, T. (2007). Responsabilidad Social Empresarial: el caso de Forestal Mininco S.A. y comunidades mapuche. Documentos de Trabajo. Serie Gestión $N^{\circ}$ 89. Centro de Gestión (CEGES) Departamento de Ingeniería Industrial Universidad de Chile. Disponible en: http://www.dii.uchile.cl/ ceges/publicaciones/89\%20ceges\%20TW.pdf

Yánez, N., y Aylwin, J. (2007). El Gobierno de Lagos, los pueblos indigenas y el "nuevo trato". Santiago de Chile: LOM.

\section{Diarios y Revistas}

La Tercera

Diario el Sur

La Nación Crónica

Diario el Sur

El Mercurio

Ciper Chile

Recibido: 4 de Junio de 2020

Aceptado: 16 de Julio de 2020

Versión Final: 23 de Agosto de 2020 